\title{
3-D GRACE gravity model for the 2011 Japan earthquake
}

\author{
Rambhatla G Sastry* and Mahendra K Sonker \\ Department of Earth Sciences, Indian Institute of Technology Roorkee, Roorkee 247 667, India. \\ *Corresponding author.e-mail: rgss1fes@iitr.ac.in/rgssastry@gmail.com
}

The GRACE mission has contributed to the seismic characterization of major earthquakes in offshore regions of the world. Here, we isolate satellite gravity signal ( $\mu$ Gal range) for the Japan Earthquake of 2011 using a difference method. Contrary to the existing gravity models, we propose a unit vertical pyramid based five-layer 3-D thrust fault model, which extends to the hypocenter and honors the ocean water layer and sea floor upheaval also. Our model partly uses existing seismological information (hypocenter depth of $32 \mathrm{~km}$, rupture length of $300 \mathrm{~km}$ and vertical slip of $4 \mathrm{~m}$ ), provides a snapshot of episodic subduction of the Pacific Plate below the Atlantic Plate and its gravity response closely matches the observed gravity (RMS error of $3.4012 \times 10^{-13} \mu \mathrm{Gal}$ ), fully accounting for co-seismic mass redistribution including sea surface deformation. Our inferred rupture length, rupture velocity, average seismic moment magnitude and momentum, respectively, are $300 \mathrm{~km}, 4.49 \mathrm{~km} / \mathrm{s}, 1.152 \times 10^{21}-1.8816 \times 10^{21} \mathrm{~N} \mathrm{~m}$ and $2.319 \times 10^{6} \mathrm{GNs}$, which fairly agree with the literature. Further, our model inferred momentum at the sea floor corresponds to an area pulse that led to Tsunami generation.

\section{Introduction}

The GRACE (Gravity Recovery and Climate Experiment) satellite has enormously contributed towards a spatiotemporal understanding of Earth's dynamic gravity field (Cazenave and Chen 2010), including mass redistribution related to major earthquakes (DeViron et al. 2008). GRACE gravity (Tapley et al. 2004), detects the gravity signatures associated with co-seismic and post-seismic deformation due to great undersea earthquakes (Han et al. 2006; Chen et al. 2007; Heki and Matsuo 2010; Simons et al. 2011; Wang et al. 2012). The importance of the ocean layer, the location of rupture and the determination of earthquake parameters from GRACE observations were reported (Broerse et al. 2014).

The GRACE satellite spatial resolution in mid-latitudes is a circle of about $300 \mathrm{~km}$ (private communication from Dr V Zlotnicki, victorzlotnicki @jpl.nasa.gov) and related gravity is sensitive to the width of the earthquake rupture (Wang et al. 2012). Further, the spatial resolution increases with latitude (Wang et al. 2012).

Plafker (1972) has undertaken dip-slip mass movements related to two mega-thrust earthquakes of the 1960 Chile earthquake and the 1964 Alaska earthquake. Several workers computed the seismic moment magnitude and its variation with depth, rake, dip, rupture length, rupture velocity of the 2011 Japan earthquake by inversion of GRACE gravity data (Gilbert and Backus 1968; Okubo 1992; Sun and Okubo 1993, 1998; Pollitz 1997, 2011; Han et al. 2011; Hayes 2011; Wang et al. 2012) and GPS data (Nettles et al. 2011; Wang et al. 2012). Gilbert and Backus (1968) studied the elastic gravitational response of radially stratified earth model. Okubo (1992) has presented

Keywords. GRACE gravity; 2011 Tohoku-Oki earthquake; gravity pyramid model; tsunamigenic earthquake. 
an analytical expression for potential and gravity changes due to faulting on a finite rectangular plane buried in a homogeneous half space. Sun and Okubo $(1993,1998)$ have dealt with the potential and gravity changes caused by dislocation in spherically symmetric earth models. Pollitz (1997, 2011) has extended it to a layered spherical earth model involving spherical harmonic expansion. Sun and Okubo's formulations (Sun and Okubo 1993, 1998) for computation of elastic deformation have led to a new series of satellite gravity modelling and stress evolution and time-displacement models to create simulated slip histories (Hayes et al. 2006; Harms et al. 2015). Recently, Gokula and Sastry (2015) have proposed a vertical pyramid model for undertaking 3-D gravity forward modelling, and this model is quite flexible enough for modelling subduction zone tectonics. Gokula and Sastry (2015) have provided several synthetic models to this effect. Using the sea level equation method, Broerse et al. (2014) have modelled geoid undulation owing to ocean water movement initiated by co-seismic vertical and horizontal deformations of the sea floor of megathrust earthquakes. Geoid undulations can also be inferred from standard geodetic methods (Heiskanen and Moritz 1967; Lambeck 1990).

In the literature, traditional gravity models for GRACE satellite data following offshore earthquakes honoring upheaval in ocean bottom (thrust fault tectonics) and mass displacements up to hypocenter regions associated with subduction are rare. Here, we propose a five-layered thrust fault model (3-D forward gravity pyramid model with constant density contrasts) to explain the isolated GRACE satellite gravity anomaly at an average satellite height of $500 \mathrm{~km}$ above MSL for the 2011 Japan earthquake. Additionally, our model infers rupture length, average rupture velocity, seismic moment and momentum, independently, and they match fairly well with that of published estimates in literature.

\section{Case study}

In the present study, we have undertaken gravity signal analysis pertaining to the 2011 Japan earthquake. The magnitude 9.0 Japan earthquake of 11 March 2011 was one of the largest earthquakes ever recorded. The epicentre of the 2011 Japan (Tohoku-Oki) earthquake is $38.322^{\circ} \mathrm{N}, 142.369^{\circ} \mathrm{E}$ with a rupture length of $300 \mathrm{~km}$ (figure 1) and hypocenter $32 \mathrm{~km}$ (Fujiwara et al. 2011; Ozawa et al. 2011; Sato et al. 2011; Simons et al. 2011). Pacific plate's subduction beneath Ohotsk plate near northern Honshu has led to 2011 Japan earthquake (Japan earthquake 2011, Wikipedia).
The earthquake ruptured a section of the Japan Trench (marking the interface between the overriding North American plate and subducting lithosphere of the Pacific plate) just $\sim 300 \mathrm{~km}$ long and $\sim 150 \mathrm{~km}$ wide, with peak slips of $35 \mathrm{~m}$ or more (Ammon et al. 2011; Hayes 2011; Shao et al. 2011; Huang and Zhao 2013a; Tajima et al. 2013). The Tohoku-Oki event has deformed sea floor, land, crust and mantle surrounding the rupture region (Fujiwara et al. 2011; Sato et al. 2011).

\section{Data and methodology}

The GRACE Science Data System (Level 2 'RL_05' data product 'GX-OG-_2-GSM') of Jet Propulsion Laboratory, the University of Texas Centre for Space Research and GeoForschungs Zentrum, Potsdam (Bettadpur 2007) was considered for the present study. It is in the form of spherical harmonic coefficients up to a maximum of 90 degrees and orders.

After a systematic selection and application of several band-pass filters, a properly designed bandpass filter (30-70, degrees and orders) has isolated earthquake source related gravity signals for the months February and April, 2011, and their difference has yielded the net gravity signal for the 2011 Japan earthquake. Broad steps of our methodology are as follows:

(a) Computation of gravity potential (spherical harmonic synthesis) for pre- and post-earthquake (Tsunami) using spherical harmonic coefficients available in the public domain (http://isdc. gfz-potsdam.de), and thereby, gravity anomaly distribution for both episodes.

(b) Estimation of Tsunami (earthquake) related gravity signal by differencing pre- from postgravity anomaly distribution in the study region (figure 1).

Gravitational potential and its gradient are calculated from the spherical harmonic coefficient (90 degrees and orders) for 2011 the Japan earthquake from the following expressions:

$$
\begin{aligned}
V(r, \theta, \varphi)= & \sum_{n=0}^{\infty} \frac{1}{r^{n+1}} \sum_{m=0}^{n}\left[a_{n m} P_{n m} \cos \theta \cos (m \varphi)\right. \\
& \left.+b_{n m} P_{n m} \cos \theta \sin (m \varphi)\right] .
\end{aligned}
$$

The satellite gravity is described by the following spherical harmonic expression:

$$
\begin{aligned}
g(r, \theta, \varphi)= & \sum_{n=0}^{90} \frac{(n+1)}{r^{n+2}} \sum_{m=0}^{n}\left[a_{n m} P_{n m} \cos \theta \cos (m \varphi)\right. \\
& \left.+b_{n m} P_{n m} \cos \theta \sin (m \varphi)\right]
\end{aligned}
$$



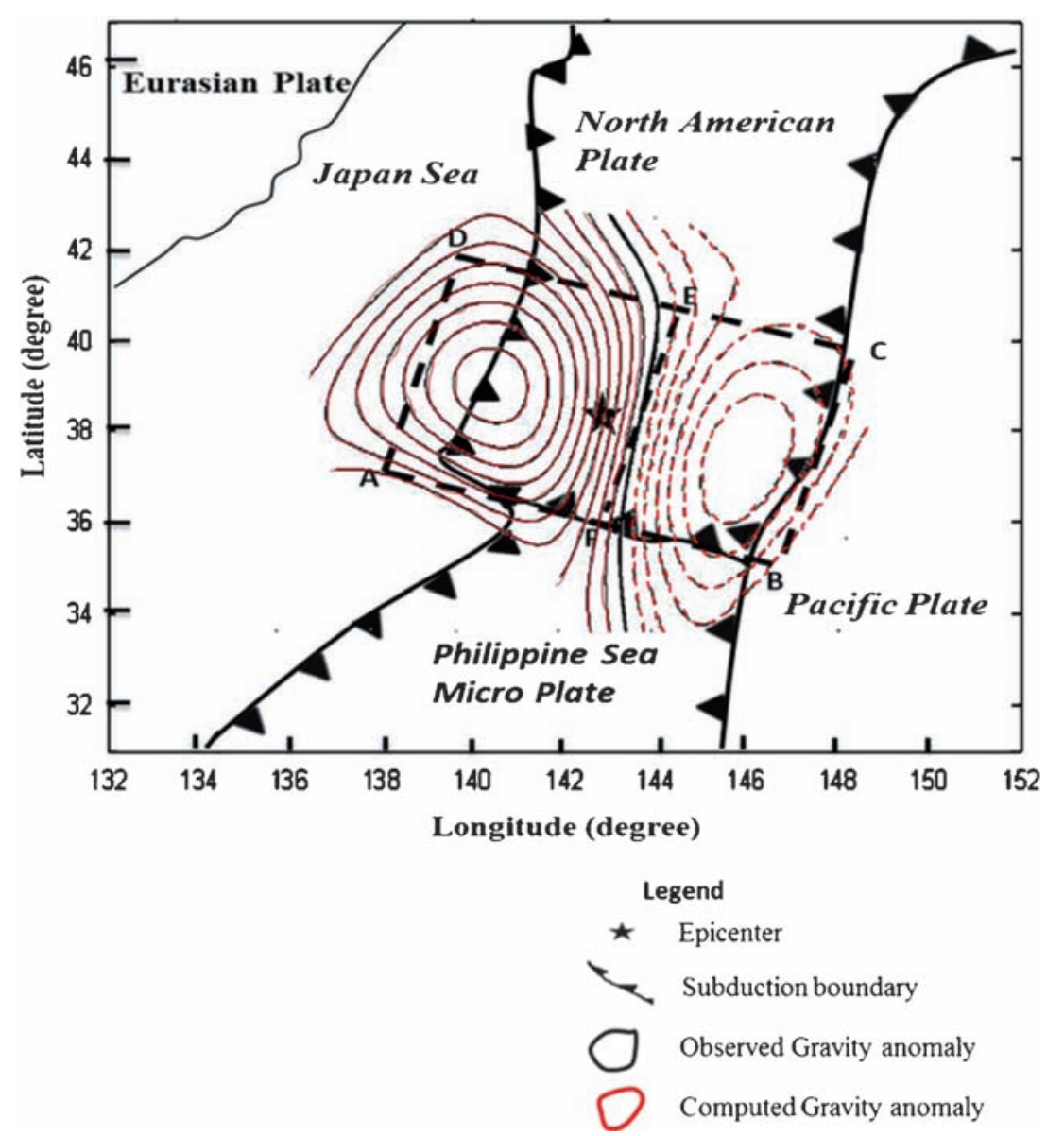

Figure 1. Our isolated GRACE satellite gravity map with superimposed 3-D forward gravity model response at a mean satellite height of $500 \mathrm{~km}$ above MSL with a relevant background tectonic map of 2011 Japan earthquake. The tectonic map depicts Eurasian, North American, Pacific and Philippine sea micro-plate boundaries. Epicenter of 2011 Japan earthquake is also shown. Bold zero anomaly contour delineates the fault trace. The solid and dashed contours outline negative and positive gravity responses of our model (red) and observed (black) gravity anomalies. Gravity anomaly values are in the range -0.19 to $0.14 \mu \mathrm{Gal}$. The R.M.S. error deviation of computed gravity response with that of observed gravity is $3.4012 \times 10^{-13} \mu \mathrm{Gal}$.

where $a_{n m}$ and $b_{n m}$ are the spherical harmonic coefficients of degree $n$ and order $m$ and $P_{n m}$ are the Legendre's spherical functions. Radial distance, $r$, is from the centre of the spherical earth to the satellite altitude above MSL, while $\theta$ and $\varphi$ are colatitude and longitude of the station, respectively.

(c) Based on available geophysical constraints in published literature, a 3-D five layered gravity model is framed. However, the co-seismic top sea water layer deformation can be computed using geoidal height variation (Heiskanen and Moritz 1967; Lambeck 1990). It involves computation of geoidal heights using GRACE datasets for both pre- and post-earthquake events. Further geoidal undulation, $N$ is given by $N=T / \gamma$, where $T$ and $\gamma\left(=G M / R^{2}\right)$ are respectively disturbing potential and normal gravity on spherical Earth. Broerse et al. (2014) have attempted it through a complicated sea level. (d) 3D forward gravity modelling for the 2011 Japan earthquake source region using a unit vertical pyramid model (Gokula and Sastry 2015).

(e) Estimation of rupture velocity, seismic moment and seismic momentum on the basis of excess mass derivable from step (d) above.

\subsection{Rupture velocity computation}

The total energy (http://alabamaquake.com/index. html) released for an earthquake of magnitude M9.0 is equated to kinetic energy, which involves excess mass and rupture velocity. So, by considering the total excess mass for our gravity model one can estimate the rupture velocity.

\subsection{Seismic momentum estimation}

It involves a product of excess mass and rupture velocity. 


\subsection{Seismic moment estimation}

Seismic moment is calculated by multiplying the shear modulus, the fault surface area and the width of the fault surface ( $\mu \mathrm{SD})$.

\section{Results}

By using the earlier mentioned methodology, relevant gravity anomaly distribution (figure 1) is obtained. We have undertaken a $3-\mathrm{D}$ gravity forward modelling using the unit vertical pyramid model (Gokula and Sastry 2015). The layer-wise forward gravity responses of our model (figure 2) are included in figure 3 and their combined response in figure 1 . The RMS error between observed and computed gravity is $3.4012 \times 10^{-13} \mu \mathrm{Gal}$.

According to our 3-D model, the seismic moment is $1.152 \times 10^{21}-1.8816 \times 10^{21} \mathrm{~N} \mathrm{~m}$ for shear modulus in the range 30-49 GP (Kagan and Jackson 2013). The computed rupture velocity, rupture length and momentum for displaced actual mass of our model are $4.49 \mathrm{~km} / \mathrm{s}, 300 \mathrm{~km}$ and $2.319 \times 10^{6}$ GNs, respectively, with the assumption that a

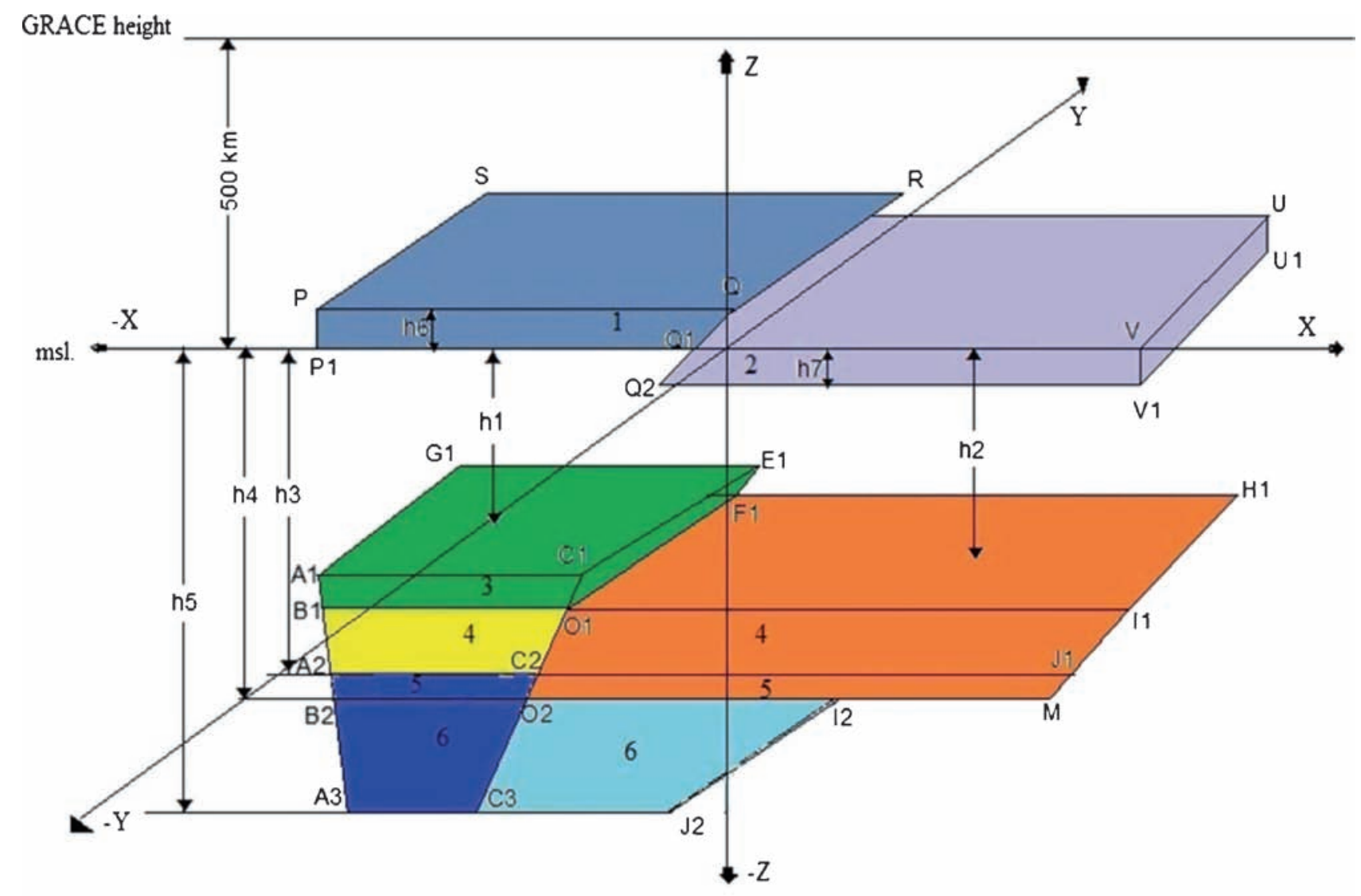

Densities (gm./cc)

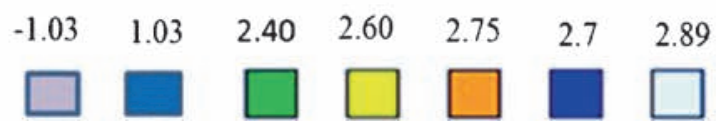

Figure 2. Schematic diagram explaining our gravity model (dimensions and bulk densities). The unit model is a pyramid, whose analytic gravity response is available in recent literature (Gokula and Sastry 2015). Numerals 1-5 indicate different layers in our gravity model. Dip angle, $\theta=25^{\circ}$. The pyramid vertices in different layers are as follows: $\mathrm{P}(-421$, $\left.-150,10^{-6}\right) ; \mathrm{P} 1(-421,-150,0) ; \mathrm{Q}\left(0,-150,10^{-6}\right) ; \mathrm{Q} 1\left(-2.14 \times 10^{-6},-150,0\right) ; \mathrm{R}\left(0,150,10^{-6}\right) ; \mathrm{R} 1\left(-2.14 \times 10^{-6}\right.$, $150,0) ; \mathrm{S}\left(-421,150,10^{-6}\right) ; \mathrm{S} 1(-421,150,0) ; \mathrm{Q} 2\left(-4.3 \times 10^{-6},-150,-10^{-6}\right) ; \mathrm{V}(480,-150,0) ; \mathrm{V} 1\left(480,-150,-10^{-6}\right)$; $\mathrm{U}(480,150,0)$; U1 $\left(480,150,-10^{-6}\right) ; \mathrm{A} 1(-421,-150,-0.585) ; \mathrm{B} 1(-415,-150,-0.589) ; \mathrm{B} 1^{\prime}(-415,150,-0.589)$; $\mathrm{C} 1(0,-150,-0.585)$; D1(-0.009, - 150, -0.589); E1(0, 150, -0.585); F1(-0.009, 150, -0.589); G1(-421, 150, -0.585); $\mathrm{A} 2(-265,-150,-8.589) ; \mathrm{A} 2^{\prime}(-265,150,-8.589) ; \mathrm{C} 2(-17.16,-150,-8.589) ; \mathrm{C}^{\prime}(-17.16,150,-8.589) ; \mathrm{I} 1(480,-150$, $-0.589)$; J1(380, -150, -8.589); H1(480, 150, -0.589); K1(380, 150, -8.589); B2(-255, - 150, -8.593); B2' (-255, $150,-8.593) ; \mathrm{D} 2(-17.17,-150,-8.593) ; \mathrm{D}^{\prime}(-17.17,150,-8.593) ; \mathrm{M}(378,-150,-8.593) ; \mathrm{M}^{\prime}(378,150,-8.593)$; $\mathrm{I} 2(270,-150,-8.593) ; \mathrm{I}^{\prime}(270,150,-8.593) ; \mathrm{A} 3(-205,-150,-32.593) ; \mathrm{A} 3^{\prime}(-205,150,-32.593) ; \mathrm{C} 3(-68.64,-150$, $-32.593)$; $\mathrm{C}^{\prime}(-68.64,150,-32.593) ; \mathrm{J} 2(-60,-150,-32.593) ; \mathrm{J}^{\prime}(-60,150,-32.593)$. 

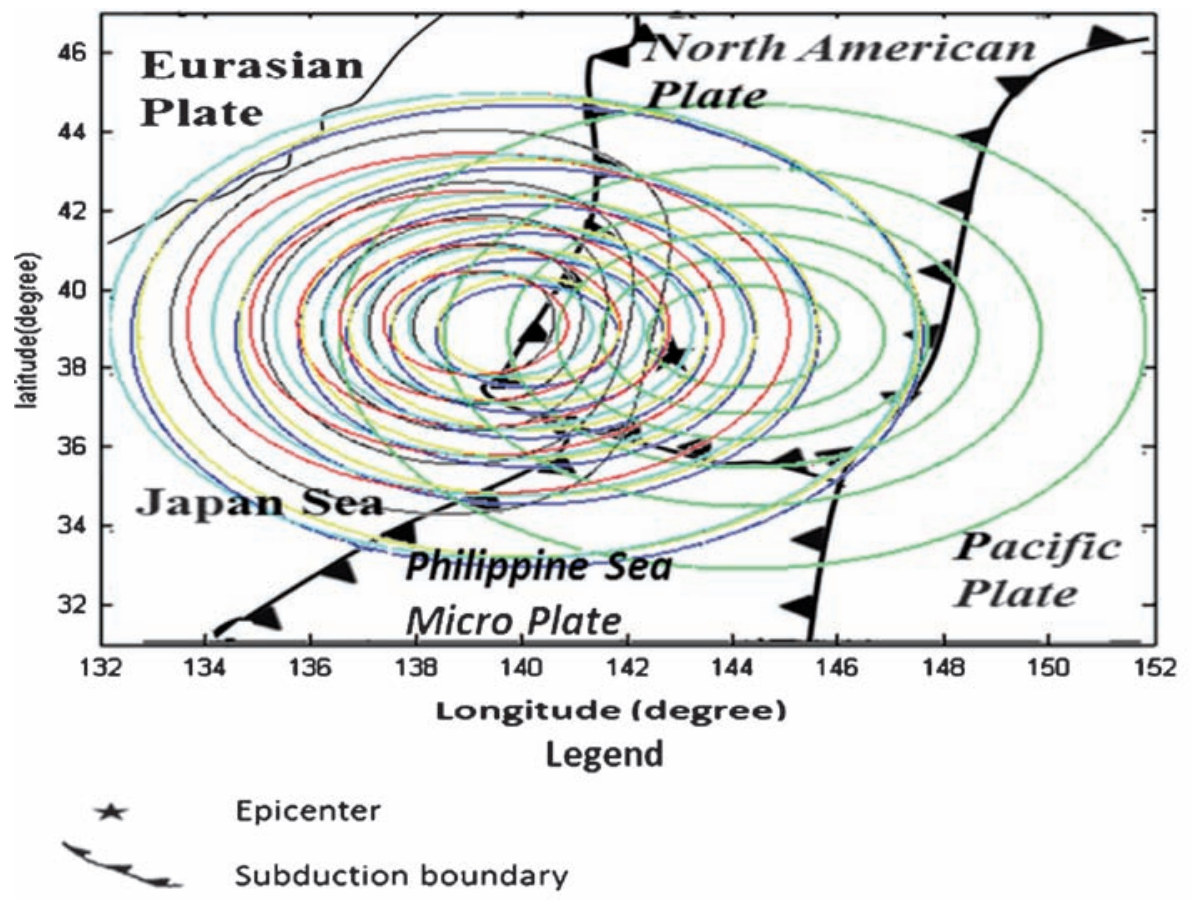
(a)
(b)
Up-thrown water layer response
Down-thrown water layer response
f First layer
(c)
Second layer response
(e)
e) Fourth layer response
(d)
Third layer response
(f)
Fifth layer response

Figure 3. Gravity responses ( $\mu \mathrm{Gal}$ ) of our 3-D five-layered model (figure 2). (a) Up-thrown water layer (gravity anomaly range $(5.05-26.44) \times 10^{-7}$ with a contour interval of $0.43 \times 10^{-7}$ ) - Blue colour. (b) Down-thrown water layer (Gravity anomaly range $(-29.49$ to -5.63$)) \times 10^{-7}$ with a contour interval of $\left.-0.47 \times 10^{-7}\right)$ - Green colour. (c) Ocean floor (second layer) (gravity anomaly range 3.11-13.60 with a contour interval of 2.63) - Red colour. (d) Oceanic crust (third layer) (gravity anomaly values $(-1.5798$ to -0.36$) \times 10^{4}$, with a contour interval of $\left.-0.31 \times 10^{4}\right)-$ Yellow colour. (e) Fourth layer (gravity anomaly values $(-9.14$ to -2.08$)$, with a contour interval of -1.76 ) - Light Blue colour. (f) Fifth layer (gravity anomaly values $(0.40-1.58) \times 10^{4}$, with a contour interval of $\left.0.30 \times 10^{4}\right)-$ Black colour.

total seismic moment energy $3.8995 \times 10^{22}$ joules is associated with an earthquake of magnitude 9.0 (http://alabamaquake.com/index.html).

\section{Discussion}

Table 1 contains the details of seismic constraints and estimated parameters in published literature, which includes the ones related to our model. In table 2, we compare the different GRACE gravity data isolation adopted by various authors. Analysis of this table clearly shows that our data set is the closest one to co-seismic event. Table 3 vividly outlines the rationale for the choice of dimensions for individual layers along with density distribution. In table 4, we compare the details in our model with available literature values. It also enlists our isolated gravity response both at MSL and satellite height. The entire gravity modelling has been undertaken for isolated anomaly at satellite height only unlike reported results in published literature. This table will clarify the matters concerned.

In figure 1, we include forward gravity response, isolated gravity anomaly and projection of our gravity model in the background tectonic framework of the 2011 Japan earthquake. As forward response best fits the observed (RMS error of $\left.3.4012 \times 10^{-13} \mu \mathrm{Gal}\right)$, both contours merge with each other. Figure 2 is a schematic explaining our 5-layered 3-D gravity model. All relevant coordinates of pyramid corners and densities of different layers are mentioned in it. In figure 3 , the superimposed individual forward responses of all five layers are included in different colours. The total gravity effect is included in figure 1 as indicated earlier.

\subsection{GRACE satellite gravity processing and our forward gravity model}

Our difference method of isolating GRACE satellite gravity signal (table 2) is simple and straightforward. 


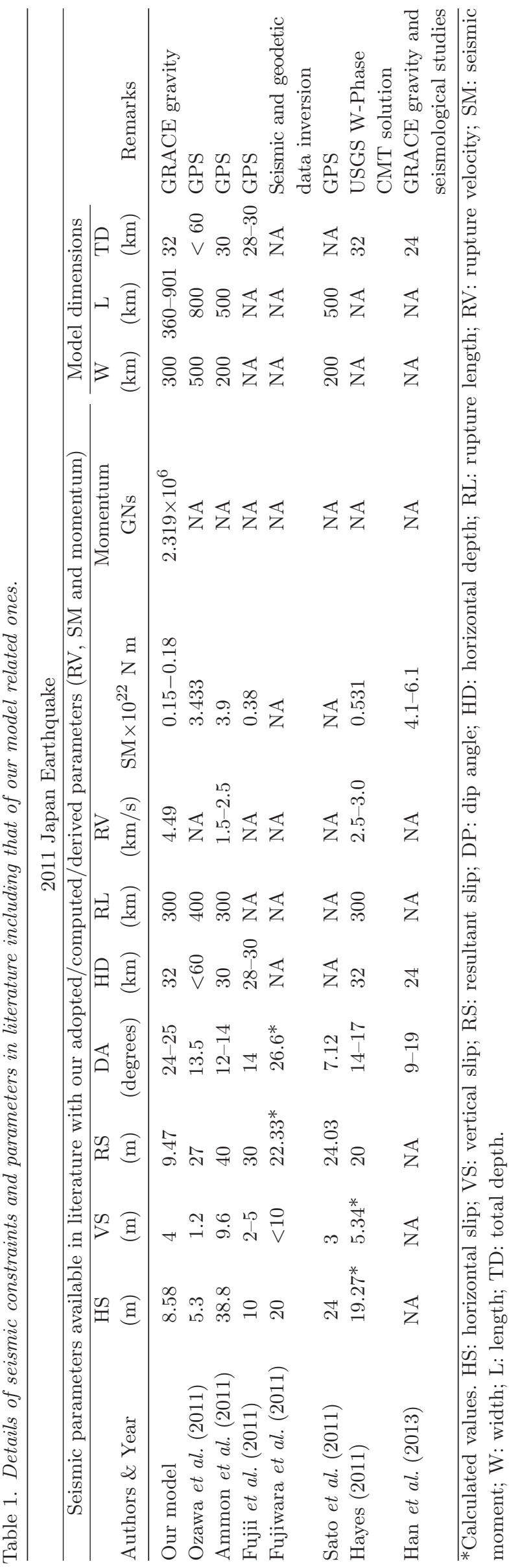

The isolated gravity anomaly pattern conforms to thrust fault environment associated with the subduction process at the ocean bottom and it agrees in sign with published literature (Cazenave and Chen 2010; Cambiotti and Sabadini 2013; Broerse et al. 2014) as it involved differencing pre- (monthly average gravity for February 2011) from post-earthquake (monthly average gravity for April 2011) gravity signal attended by bandpass filtering (30-70 spherical harmonic degree and order).

Our 3-D forward thrust fault gravity model (figure 2) has a rupture length of $300 \mathrm{~km}$ with a vertical slip of $4 \mathrm{~m}$ and slope of 25 degrees at the ocean bottom (Hayes 2011; Ozawa et al. 2011; Simons et al. 2011; Sato et al. 2011). This simple model at sea bottom had a forward gravity response amplitude of $13.6 \mu \mathrm{Gal}$ (figure 3 (red contours)) far exceeding the observed satellite gravity anomaly (figure 1 (black contours)). So, we have considered a 5-layered 3-D thrust fault model, whose top first layer $\left(-1 \times 10^{-6}\right.$ to $\left.1 \times 10^{-6} \mathrm{~km}\right)$ is a deformed sea surface, the second layer $(-0.584$ to $-0.589) \mathrm{km}$ ) coincides with the ocean floor and third layer corresponds to oceanic crust $(-0.589$ to $-8.589 \mathrm{~km}$ ) with respective gravity responses, as shown in figure 3 (yellow contours). The transition fourth layer (figure 2) is introduced (-8.589 to $-8.993 \mathrm{~km}$ ) for accommodating the gravity responses from the third and fifth layers. The 5th layer extends up to hypocenter $(-32.993 \mathrm{~km})$ with a negative density contrast $(-0.19 \mathrm{gm} / \mathrm{cc})$, as per isostasy requirement. The overlapping of first, second, third, fourth and fifth layers are included in figure 3 in blue and green, red, yellow, light blue and black contours, respectively. The combined response of the entire model is superimposed in figure 1 (red contours), which closely matches the observed (figure 1, black contours) gravity (RMS error of $\left.3.4012 \times 10^{-13} \mu \mathrm{Gal}\right)$.

Our gravity model differs from widely held formulations (Okubo 1992; Sun and Okubo 1993, 1998) and further studies based on them (Hayes et al. 2006; Cambiotti and Sabadini 2013; Han et al. 2013; Schultz et al. 2014; Harms et al. 2015). Rather, it follows a more traditional route of gravity forward modelling involving depth-wise density variation and the concept of Isostasy (Watts 2001).

\subsection{Earlier models vis-à-vis our model}

Even though we have not included reported GPS measurements (Sato et al. 2011), we estimated the resultant slips at several points. Accordingly, average vertical, horizontal and dip slips worked out to be $1.56,16.4$ and $16.48 \mathrm{~m}$. These estimates helped in shaping our current model (figure 2). 
Table 2. Inter-comparison of GRACE gravity datasets used by various authors including us.

\begin{tabular}{ll}
\hline Authors & $\begin{array}{c}\text { Duration of GRACE datasets considered } \\
\text { (monthly average spherical harmonic coefficients) }\end{array}$ \\
\hline Broerse et al. $(2014,2011)$ & 2 years before and 5 years after the earthquake \\
Cambiotti and Sabadini $(2012,2013)$ & January 2009-December 2011 \\
Han et al. $(2013)$ & April 2002-September 2012 \\
Han et al. $(2014)$ & February 2008-December 2013 \\
Wang et al. $(2012)$ & January 2005-July 2011 \\
Our attempt & February 2011-April 2011 \\
\hline
\end{tabular}

Table 3. Adopted density distribution, satellite height and average depth of ocean floor for our gravity model with relevant literature details and remarks.

Geophysical constraints for our model with relevant remarks

\begin{tabular}{|c|c|}
\hline Depths and densities for our gravity model & Published literature \\
\hline Satellite height above MSL & 500 km (Tapley et al. 2004; Cambiotti and Sabadini 2013) \\
\hline Co-seismic deformation of sea surface water (First layer) & $\begin{array}{l}\text { We independently computed the difference of geoid } \\
\text { undulations }(N=T / \gamma) \text { for both pre- and } \\
\text { post-earthquake using GRACE datasets } \\
\text { (Heiskanen and Moritz } 1967 \text {; Lambeck } 1990) \text {, where } T \text { and } \\
\gamma\left(=G M / R^{2}\right) \text { are disturbing potential and normal gravity on } \\
\text { spherical Earth, respectively. Broerse } \text { et al. (2014) have } \\
\text { attempted it through a complicated Sea Level Equation }\end{array}$ \\
\hline Average depth of ocean floor below MSL & Using Topex (http://topex.ucsd.edu) \\
\hline Deformation of ocean floor (Second layer) & $\begin{array}{l}\text { Vertical displacement of ocean floor using published GPS } \\
\text { literature (Hayes 2011; Sato et al. 2011). Choice of density } \\
\text { values of second to fifth layers of our gravity model are as } \\
\text { per Cambiotti and Sabadini (2013) and Lowrie (2007) }\end{array}$ \\
\hline Oceanic crust (Third layer) & Depth is constrained by Han et al. (2013) and Lowrie (2007) \\
\hline Fourth layer & $\begin{array}{l}\text { This thin sandwiched layer is considered for achieving a close } \\
\text { fit between observed and computed gravity anomalies. }\end{array}$ \\
\hline Fifth layer & $\begin{array}{l}\text { Hypocenter depth is constrained by seismological information } \\
\text { (Ammon et al. 2011; Hayes 2011) }\end{array}$ \\
\hline
\end{tabular}

Broerse et al. (2014) have outlined co-seismic gravity results for the 2011 Japan earthquake based on Hooper et al. (2013) and Hayes (2011) earthquake slip models along with gravity effect of displaced ocean water mass. Now, we have evaluated the co-seismic deformation of surface water layer based on geoid height computations (table 4). Further, our gravity model (figure 2) and its total response (shown in red colour contours in figure 1) fully accounts for the observed GRACE gravity anomaly (shown in black colour contours in figure 1), while Broerse et al. (2014) have only considered gravity peak positive and negative values with depth. Further, the Hayes (2011) and Hooper et al. (2013) models do not fully account for co-seismic vertical deformation at Japan Trench (Broerse et al. 2014), as per their own admission. However, Broerse et al. (2014) predicted a horizontal slip of $66 \mathrm{~m}$ in the vicinity of Japan Trench for $16.4 \mathrm{~m}$ on the land portion, which means a four-fold increase.
The same logic, if extended to the vertical slip, can readily match our vertical slip of $4 \mathrm{~m}$.

Thus, our model (figure 2) fully accounts for both vertical $(4 \mathrm{~m})$ and horizontal deformations $(8.58 \mathrm{~m})$ with a dip-slip of $9.47 \mathrm{~m}$ at a dip angle of $25^{\circ}$. Using the Hayes (2011) slip model (resultant slip of $16 \mathrm{~m}$ ) by assuming a vertical slip of $4 \mathrm{~m}$, the maximum dip angle could be of the order $14.5^{\circ}$, which is roughly half that of our estimate. It may be mentioned that for a better match of computed gravity anomaly (shown in red colour contours in figure 1) with that of the input gravity anomaly map (shown in black colour contours in figure 1), it was necessary to assume the dip angle of thrust fault (figure 2) to be $25^{\circ}$. However, our forward gravity model is flexible enough to reduce the fault model parameters, including the dip angle to honor the prevalent low dip values (Hayes 2011; Broerse et al. 2014), but it would lead to a more complex multi-layered thrust model. As a maiden attempt, 


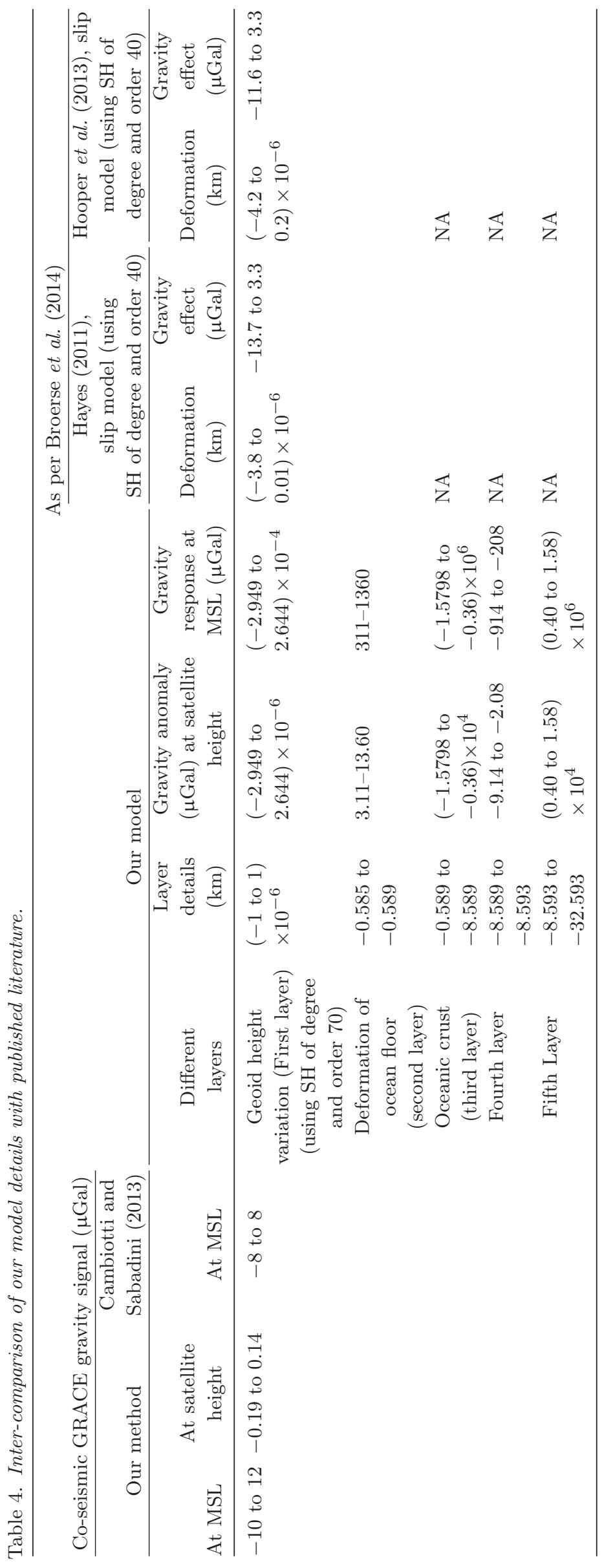


we retain our current model, which characterises the co-seismic gravity anomaly source. It honours both horizontal (Broerse et al. 2014) and vertical slips and water mass displacement (Broerse et al. 2014).

As per Ide et al. (2011), the 2011 Japan earthquake nucleated near the deeper zone, but moved updip to the shallow zone near the trench, then back down-dip towards the coast, thereby attaining its great size in part by a longer dimension down-dip. This change in dip of the subduction zone is partly accommodated by an abrupt change in subducting Pacific Plate dimensions at Conrad depth level in our proposed gravity model, as shown schematically in figure 2. A more intricate gravity model can honor such change in dips also. It may also be mentioned that the depth-wise decrement in model volume is commensurate with aftershock area distribution (Zhao 2015).

Zhao (2015) using high-resolution seismic tomography have inferred low-velocity patches in subduction zones and it readily matches our deficit mass associated with the overthrusted Atlantic Plate block with the Pacific Plate beneath in our gravity model (figure 2). As per Hayes (2011), the rupture velocity and maximum slip for the 2011 Japan earthquake are $1.25-3.25 \mathrm{~km} / \mathrm{s}$ and 100 m. Further, as rupture velocities reach $2.0 \mathrm{~km} / \mathrm{s}$, peak slips reach the top layers of the model and expand bilaterally along the shallowest sub-faults as rupture velocities increase further. Rupture lengths vary from $\sim 150 \mathrm{~km}$, with $V_{\mathrm{r}}=1.0 \mathrm{~km} / \mathrm{s}$, to $\sim 300 \mathrm{~km}$, with $V_{\mathrm{r}}=3.0 \mathrm{~km} / \mathrm{s}$ (Hayes 2011). The GRACE-estimated moment for the total slip up to the end of July 2011 is $(4.59 \pm 0.49) \times 10^{22} \mathrm{~N} \mathrm{~m}$ (Gilbert and Backus 1968; Okubo 1992; Sun and Okubo 1993, 1998; Pollitz 1997, 2011; Wang et al. 2012). If the moment for the Tohoku-Oki main shock is assumed to be $3.8 \times 10^{22} \mathrm{~N} \mathrm{~m}$, the contribution from the after-slip is $3.0 \times 10^{21}-12.8 \times$ $10^{21} \mathrm{~N}$ m (Nettles et al. 2011; Wang et al. 2012). In order to obtain source slip distribution models, several inversion studies for different types of data sets were undertaken (Umino et al. 1995; Wang and Zhao 2005; Gamage et al. 2009; Huang et al. 2011a, b; Lee 2011; Simons et al. 2011; Yokota et al. 2011; Huang and Zhao 2013a, b). Our inferred average rupture velocity, rupture length, seismic moment and momentum are comparable to similar quantities in literature (Fujiwara et al. 2011; Hayes 2011; Ide et al. 2011; Nettles et al. 2011; Ozawa et al. 2011; Sato et al. 2011; Shao et al. 2011; Simons et al. 2011; Wang and Mori 2011a; Wang et al. 2012). However, our seismic moment is one order less than which is published is literature (Hayes 2011; Nettles et al. 2011; Shao et al. 2011; Simons et al. 2011; Wang et al. 2012). But, if we consider the deficit mass instead of true mass in our computation, we obtain a similar estimate for seismic moment.

\section{Conclusions}

The GRACE satellite gravity response for the 2011 Japan Earthquake has been isolated by a difference method and a five-layered 3D Thrust Fault gravity model extending from the ocean bottom to the hypocenter was proposed. Our RMS error fit of $3.4012 \times 10^{-13} \mu \mathrm{Gal}$ for computed gravity response to the GRACE gravity data fairly honors observed anomaly data.

Earlier gravity models are based on formulations of Okubo (1992) and Sun and Okubo (1993, 1998). However, following a traditional procedure, our 3-D (five layered) thrust fault model extending from the sea surface to the hypocenter depth and its forward response fully explains the origin of observed (isolated) satellite gravity signal for the 2011 Japan earthquake (Tsunami) source and in that respect our results are novel. Inferred average rupture velocity, minimum rupture length, seismic moment and momentum are respectively, 4.49 $\mathrm{km} / \mathrm{s}, 300 \mathrm{~km}, 1.152 \times 10^{21}-1.8816 \times 10^{21} \mathrm{~N} \mathrm{~m}$ and $2.319 \times 10^{6} \mathrm{GNs}$, which match well with respective values in literature. Our gravity model inferred momentum corresponds to an area pulse at the ocean bottom, which served as Tsunami source pulse. More intricate gravity models answering shallow under-thrusting of Pacific plate satisfying other geophysical constraints are underway.

\section{Acknowledgements}

We gratefully acknowledge the help received from Mr Aruj Pant, a post-graduate student under the first author, in isolation of satellite gravity signal of the 2011 Japan earthquake and Mr Anand Gokula for the gravity forward modelling software of right vertical pyramid model. Mr Sonker is thankful to the Ministry of Human Resources Development (MHRD), Government of India, for financial support.

\section{References}

Ammon C J, Lay T, Kanamori H and Cleveland M 2011 A rupture model of the 2011 off the Pacific coast of Tohoku earthquake; Earth Planets Space 63 693-696.

Bettadpur S 2007 Product specification document Rev 4.5. GRACE, pp. 327-720p.

Broerse D, Vermeersen L, Riva R and Van der Wal W 2011 Ocean contribution to co-seismic crustal deformation and geoid anomalies: Application to the 2004 December 26 Sumatra-Andaman earthquake; Earth Planet. Sci. Lett. 305(3-4) 341-349. 
Broerse T, Riccardo R and Bert V 2014 Ocean contribution to seismic gravity changes: The sea level equation for seismic perturbations revisited; Geophys. J. Int. 199 1094-1109.

Cambiotti G and Sabadini R 2013 Gravitational seismology retrieving centroid-moment tensor solution of the 2011 Tohoku earthquake; J. Geophys. Res. Sol. Ea. 118(1) 183-194.

Cazenave A and Chen J 2010 Time-variable gravity from space and present-day mass redistribution in the Earth system; Earth Planet. Sci. Lett. 298(3-4) 263-274.

Chen J L, Wilson C R, Tapley B D and Grand S 2007 GRACE detects coseismic and postseismic deformation from the Sumatra-Andaman earthquake; Geophys. Res. Lett. 34 L13302.

DeViron O, Panet I, Mikhailov V, Van Camp M and Diament M 2008 Retrieving earthquake signature in grace gravity solution; Geophys. J. Int. 174 14-20.

Fujii Y, Satake K, Sakai S, Shinohara M and Kanazawa T 2011 Tsunami source of the 2011 off the Pacific coast of Tohoku earthquake; Earth Planets Space 63 815-820.

Fujiwara T, Kodaira S, No T, Kaiho Y, Takahashi N and Kaneda Y 2011 The 2011 Tohoku-Oki earthquake: Displacement reaching the trench axis; Science $\mathbf{3 3 4} 1240$.

Gamage S, Umino N, Hasegawa A and Kirby S 2009 Offshore double-planed shallow seismic zone in the NE Japan forearc region revealed by SP depth phases recorded by regional networks; Geophys. J. Int. 178 195-214.

Gilbert F and Backus G 1968. Elastic gravitational vibrations of a radially stratified sphere; In: Dynamics of structured solids (ed.) Harmann G; American Society of Mechanical Engineers, pp. 82-95.

Gokula A and Sastry R G 2015 Gravitational attraction of a vertical pyramid model of flat top and bottom with depth-wise linear density variation; Curr. Sci. 109(10) 1864-1868.

Han S C, Shum C K, Bevis M, Ji C and Kuo C Y 2006 Crustal dilatation observed by GRACE after the 2004 Sumatra-Andaman earthquake; Science $\mathbf{3 1 3}$ 658-661.

Han S C, Sauber J and Riva R 2011 Contribution of satellite gravimetry to understanding seismic source processes of the 2011 Tohoku-Oki earthquake; Geophys. Res. Lett. 38(24), doi: 10.1029/2011GL049975.

Han S C, Riva R, Sauber J and Okal E 2013 Source parameter inversion for recent great earthquakes from a decadelong observation of global gravity fields; J. Geophys. Res. 118 1240-1267.

Han S C, Sauber J and Pollitz F 2014 Broadscale postseismic gravity change following the 2011 Tohoku-Oki earthquake and implication for deformation by viscoelastic relaxation and afterslip; Geophys. Res. Lett. GL060905.

Harms J, Ampuero J P, Barsuglia M, Chassande-Mottin E, Montagner J P, Somala S N and Whiting B F 2015 Transient gravity perturbations induced by earthquake rupture; Geophys. J. Int. 201 1416-1425.

Hayes T J, Tiampo K F and Fernandez J 2006 Gravity changes from a stress evolution earthquake simulation of California; J. Geophys. Res. 111 B09408.

Hayes G P 2011 Rapid source characterization of the Mw 9.0 off the Pacific coast of Tohoku earthquake; Earth Planets Space 63 529-534.

Heiskanen W A and Moritz H 1967 Physical Geodesy; W H Freeman, San Francisco.

Heki K and Matsuo K 2010 Coseismic gravity changes of the 2010 earthquake in central Chile from satellite gravimetry; Geophys. Res. Lett. 37 L24306.

Hooper A, Pietrzak J, Simons W, Cui H, Riva R, Naeije M, Terwisschavan Scheltinga A, Schrama E, Stelling G and Socquet A 2013 Importance of horizontal seafloor motion on tsunami height for the $2011 \mathrm{Mw}=9.0$ TohokuOki earthquake; Earth Planet. Sci. Lett. 361 469479 .

Huang Z, Zhao D and Wang L 2011a Seismic heterogeneity and anisotropy of the Honshu arc from the Japan Trench to the Japan Sea; Geophys. J. Int. 184 1428-1444.

Huang Z, Zhao D and Wang L 2011b Shear-wave anisotropy in the crust, mantle wedge and the subducting Pacific slab under Northeast Japan; Geochem. Geophys. Geosys. 12 Q01002.

Huang Z and Zhao D 2013a Mechanism of the 2011 TohokuOki earthquake (Mw 9.0) and Tsunami: Insight from seismic tomography; J. Asian Earth Sci. 70 160-168.

Huang Z and Zhao D 2013b Relocating the 2011 Tohoku-Oki earthquakes (M 6.0-9.0 of the southern Kuril arc: Insight into megathrust earthquakes; Geophys. J. Int. 194 1069-1090.

Ide S, Baltay A and Beroza G C 2011 Shallow dynamic overshoot and energetic deep rupture in the $2011 \mathrm{Mw} 9.0$ Tohoku-Oki earthquake; Science 332 1426-1429.

Kagan Y Y and Jackson D D 2013 Tohoku Earthquake: A surprise? BSSA 103(2B) 1181-1194.

Lambeck K 1990 Aristoteles - An ESA Mission to study the earth's gravity field; ESA J. 14 1-21.

Lowrie W 2007 Fundamentals of geophysics; Swiss Federal Institute of Technology, Zürich.

Lee S J 2011 Rupture process of the 2011 Tohoku-Oki earthquake based upon joint source inversion of teleseismic and GPS data; Terr. Atmos. Ocean Sci. 23 1-7.

Nettles M, Ekstrom G and Koss H C 2011 Centroid-momenttensor analysis of the 2011 off the Pacific coast of Tohoku earthquake and its larger foreshocks and aftershocks; Earth Planets Space 63 519-523.

Okubo S 1992 Gravity and potential changes due to shear and tensile faults in a half-space; J. Geophys. Res. 97 7137-7144.

Ozawa S, Nishimura T, Suito H, Kobayashi T, Tobita M and Imakiire T 2011 Coseismic and post-seismic slip of the 2011 magnitude-9 Tohoku-Oki earthquake; Nature 475 $373-376$.

Pollitz F F 1997 Gravity anomaly from faulting on a layered spherical earth with application to central Japan; Phys. Earth Planet. I(99) 259-271.

Pollitz F F, Bürgmann R and Banerjee P 2011 Geodetic slip model of the 2011 M9.0 Tohoku earthquake; Geophys. Res. Lett. 38 L00G08.

Plafker G 1972 Alaskan earthquake of 1964 and Chilean earthquake of 1960: Implications for Arc Tectonics; J. Geophys. Res. 77(5) 901-925.

Sato M, Ishikawa T, Ujihara N, Yoshida S, Fujita M, Mochizuki M and Asada A 2011 Displacement above the hypocenter of the 2011 Tohoku-Oki earthquake; Science 3321395.

Schultz K W, Sachs M K, Heien E M, Rundle J B, Turcotte D L and Donnellan A 2014 Simulating gravity changes in topologically realistic driven earthquake fault systems: First results; Pure Appl. Geophys. 173(3) $827-838$.

Shao G, Li X, Ji C and Maeda T 2011 Focal mechanism and slip history of $2011 \mathrm{Mw} 9.1$ off the Pacific coast of Tohoku earthquake, constrained with teleseismic body and surface waves; Earth Planets Space 63559 564 .

Simons M, Minson S E, Sladen A, Ortega F, Jiang J, Owen S E, Meng L, Am-puero J P, Wei S and Chu R 2011 The 2011 magnitude 9.0 Tohoku-oki earthquake: Mosaicking the megathrust from seconds to centuries; Science $\mathbf{3 3 2}$ 1421-1425. 
Sun W and Okubo S 1993 Surface potential and gravity changes due to internal dislocations in a spherical earthI, Theory for a point dislocation; Geophys. J. Int. 114 569-592.

Sun W and OKubo S 1998 Surface potential and gravity changes due to internal dislocations in a spherical earth - II. Application to a finite fault; Geophys. J. Int. $13279-88$.

Tajima F, Mori J and Kennett B 2013 A review of the 2011 Tohoku-Oki earthquake (Mw 9.0): Large-scale rupture across heterogeneous plate coupling; Tectonophys. 586 15-34.

Tapley B D, Bettadpur S, Ries J, Thompson P and Watkins M 2004 GRACE measurements of mass variability in the Earth system; Science 305 503-505.

Umino N, Hasegawa A and Matsuzawa T 1995 SP depth phase at small epicentral distances and estimated subducting plate boundary; Geophys. J. Int. 120 356-366.

Wang Z and Zhao D 2005 Seismic imaging of the entire arc of Tohoku and Hokkaido in Japan using P-wave,
S-wave and SP depth-phase data; Phys. Earth Planet. 152(3) 144-162.

Wang D and Mori J 2011a Rupture process of the 2011 off the Pacific coast of Tohoku earthquake (Mw9.0) as imaged with back-projection of teleseismic P waves; Earth Planets Space 63 603-607.

Wang L, Shum C K, Frederik Simons J, Tapley B and Dai C 2012 Coseismic and postseismic deformation of the 2011 Tohoku-Oki earthquake constrained by GRACE gravimetry; Geophys. Res. Lett. 39 L07301.

Watts A B 2001 Isostasy and flexure of the lithosphere; Cambridge University Press, 458p.

Yokota Y, Koketsu K, Fujii Y, Satake K, Sakai S, Shinohara M and Kanazawa T 2011 Joint inversion of strong motion, teleseismic, geodetic, and tsunami datasets for the rupture process of the 2011 Tohoku earthquake; Geophys. Res. Lett. 38 L00G21.

Zhao D 2015 Tohoku earthquake ( $\mathrm{Mw}$ 9.0) sequence and subduction dynamics in Western Pacific and East Asia; J. Asian Earth Sci. 98 26-49.

MS received 18 February 2016; revised 16 September 2016; accepted 21 September 2016

Corresponding editor: N V Chalapathi RaO 